\title{
In Memory: Robert A. Laudise
}

Robert A. Laudise, Editor in Chief of Journal of Materials Research, died on August 20, 1998 at Memorial Sloan Kettering Cancer Center in New York City. Dr. Laudise served as Editor in Chief since 1994 and previously served as chair of the Advisory Review Board for the journal. Principal editor Dean Face of DuPont said, "Bob's dedication and talent have been an inspiration to the scientific community, the Materials Research Society, and to me personally. I have enjoyed serving as one of the principal editors of the Journal of Materials Research and have always admired the tremendous work that Bob has done to improve the journal and the Materials Research Society. He made serving as an editor a truly rewarding experience. I will sorely miss working with Bob, but take joy in knowing that the work he has done will have a lasting impact and has made the world a better place." Dr. Laudise's active association with MRS began with its founding 25 years ago and continued in numerous capacities until his death.

Dr. Laudise was Adjunct Chemical Director at Bell Laboratories, the research and development arm of Lucent Technologies. He joined Bell Labs in 1956 and served as Materials Research Director, Physical and Inorganic Chemistry Research Director, and Materials Processing Director. Groups he led at Bell Labs transferred optical-fiber technology to production and prepared the first lithium-niobate and yttriumaluminum garnet laser crystals. His research interests included solid-state chemistry, materials science, materials conservation, and crystal growth. Most commercial processes for preparing crystalline quartz used worldwide are based on his studies of

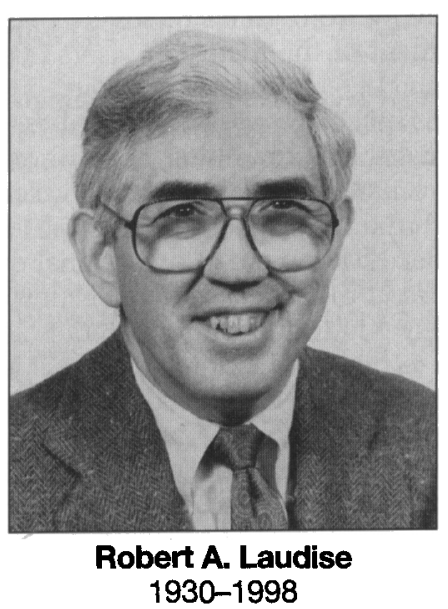

hydrothermal crystallization.

William F. Brinkman, Vice President of Bell Labs Physical Sciences and Engineering Research Division, said, "Bob was always enthusiastic about doing new things-with a sense of humor that never failed. He also had a profound commitment to industrial ecology and helped to create corporate grants at Lucent and at AT\&T that engaged researchers around the world in industrial-ecology research."

His work was widely recognized through his election to membership in the National Academy of Science and the National Academy of Engineering. He continued his personal research throughout his career, most recently in the area of crystallization of organic materials.

Dr. Laudise was also adjunct professor of materials science at the Massachusetts Institute of Technology (MIT) and adjunct professor of ceramics at Rutgers University. He received numerous prizes and awards including the American Chemical Society Materials Chemistry Prize, the International Crystal Growth Prize, the Orton Award of the American Ceramic Society, and the Sawyer Prize. In 1989 the International Organization for Crystal Growth designated its prize for experimental crystal growth the Laudise Prize.

Dr. Laudise served on numerous national advisory committees including the National Science Foundation, National Aeronautics and Space Administration, National Institute of Standards and Technology, and the President's Science Advisory Committee. He was also elected to the American Philosophical Society. His bachelor of science degree in chemistry was from Union College in Schenectady in 1952, with a PhD degree in inorganic chemistry from MTT in 1956.

MRS President Robert Nemanich said, "Bob Laudise was an original thinker whose keen insight into how scientists advance the progress of scientific research by interdisciplinary interactions was a key element in the founding of the Materials Research Society and its success over the years. After a long and distinguished career as a researcher, he brought his formidable talents and experience as a scientist to Journal of Materials Research, where as Editor in Chief his focus and drive were instrumental in further advancing the journal's role as the pre-eminent archive for interdisciplinary materials science. His contributions to MRS and to materials science are too many to list, but we would be remiss not to recall the integrity and commitment which were such strong and inseparable aspects of his style; these characteristics were part of what made him a friend to so many and admired by all." MIRS

\section{MRS Elects Officers, Councillors for 1999}

Members of the Materials Research Society have elected two officers and six councillors to join the 1999 Council, which consists of the executive committee and 15 councillors. The annual election ended October 9, 1998.

\section{MRS Officers \\ President}

Ronald Gibala (1999)

University of Michigan

Immediate Past President

Robert J. Nemanich (1999)

North Carolina State University

Vice President (President Elect)

*Harry A. Atwater (1999)

California Institute of Technology

Secretary

Chuang Chuang Tsai (1999)

Applied Komatsu Technology

Treasurer

Merrilea J. Mayo (2000)

Pennsylvania State University

\section{tInterim Treasurer}

Alan J. Hurd (through August 31, 1999)

Sandia National Laboratories

1999 MRS Councillors

Michael J. Aziz (2000)

Harvard University

Katayun Barmak (2000)

Lehigh University

*John W. Cahn (2001)

National Institute of Standards and Technology

*Anthony K. Cheetham (2001)

University of California-Santa Barbara

David J. Eaglesham (2000)

Bell Laboratories, Lucent Technologies

*A. Lindsay Greer (2001)

Cambridge University

Alexander H. King (2000)

State University of NY at Stony Brook
Karen Maex (2000)

IMEC, Belgium

*Stephen J. Pennycook (2001)

Oak Ridge National Laboratory

*Caroline A. Ross (2001)

Massachusetts Institute of Technology

Alan I. Taub (2000)

Ford Motor Company

*Rudolf M. Tromp (2001)

IBM T.J. Watson Research Center

(Terms of office expire at the end of the years indicated in parentheses.)

*Newly elected.

+Merrilea J. Mayo will assume her position as Treasurer beginning September 1, 1999 after she completes her term as OSA/MRS Congressional Fellow. Alan J. Hurd has been appointed by the MRS Executive Committee to serve as Treasurer in the interim. 